\title{
A Low-cost Device for Accurate and Continuous Measurements of Fruit Diameter
}

\author{
Brunella Morandi, Luigi Manfrini, Marco Zibordi, Massimo Noferini, \\ Giovanni Fiori, and Luca Corelli Grappadelli ${ }^{1}$ \\ Dipartimento Colture Arboree, University of Bologna, V.le Fanin 46, 40127 \\ Bologna, Italy
}

Additional index words. linear potentiometer, fruit gauge, fruit growth, Prunus persica

\begin{abstract}
This work describes a fruit gauge based on a low-cost linear potentiometer interfaced to a data-logger, which allows continuous measurement of fruit diameter. The sensor is supported by a custom-built stainless steel frame designed to be easily applied to different size fruits. Highly significant linear relationships between tension ( $\mathrm{mV}$ ) and displacement $(\mathrm{mm})$ have been found during sensor calibration. The average slope of this relationship, $5.4 \times 10^{-3}$ with a standard deviation of $5 \times 10^{-5}$, was used as conversion coefficient. Temperature stability was tested by submitting both the sensor and the whole gauge to a temperature range of 5-60 ${ }^{\circ} \mathrm{C}$. The maximum deflection found was $\pm 1 \mathrm{mV}$. Measurements performed during the three developmental stages of peach [Prunus persica (L), Batsch.] fruit showed high sensitivity of the gauge which allowed clear detection of diurnal patterns of fruit diameter changes and precise monitoring of minute variations in fruit growth rates during $24 \mathrm{~h}$.
\end{abstract}

Fruit growth dynamics has received little attention over the years. Knowledge of the daily variations in fruit size in response to environmental and physiological conditions is highly desirable, but it is hampered by the technical difficulty of measuring fruit diameter changes accurately and at a sufficiently low cost to allow proper replication of the experiments. In recent decades, continuous and precise monitoring of stem and fruit diameter changes have been carried out by automatic gauges, most often custom-built by the authors for the specific studies they intended to carry out (Araki et al., 2000; Berger and Selles, 1993; Garnier and Berger, 1986; Jones and Higgs, 1982; Përämaki et al., 2001). However, either the high cost of the components or technical difficulties in construction could hinder their use both for research and practical purposes.

The measurement of fruit diameter change is of great interest both for wholetree and single-fruit physiology research and for commercial applications, as it may provide useful information for orchard management. Several papers report fruit or stem diurnal shrinkages in response to environmental conditions and tree water status (Berger and Selles, 1993; Garnier and Berger, 1986; Jones and Higgs, 1982; Tromp, 1984). Studies on fruit growth mechanisms were made possible by precise monitoring of

Received for publication 26 Feb. 2007. Accepted for publication 18 Apr. 2007.

We gratefully acknowledge G. Tonon and M. Rieger for critical reading of the manuscript.

${ }^{1}$ To whom reprint requests should be addressed; e-mail luca.corelli@unibo.it fruit diameter changes over time, such as the daily in/outflows of phloem, xylem, and transpiration to/from the single fruit in apple (Lang, 1990) and peach (Morandi, 2006). Likewise, models to manage orchard irrigation have been developed (Huguet, 1985) and patented, complete with field systems for automatic data collection and analysis (patent numbers: US2004088916; WO02084248; WO0235193; US20020170229).

Many devices for accurate measurement of fruit growth have been developed in the past (Beedlaw et al., 1986; Higgs and Jones, 1984; Tukey, 1964). In most cases, a sensor, supported by a frame, is placed in contact with the epidermis of the growing fruit. Although supporting frames have been progressively modified and improved in their shapes and structures, the most adopted sensors are either linear variable differential transducers (LVDTs) or strain gauges. LVDT technology, though precise, accurate, and stable under field conditions, is expensive; strain gauges are cheaper than LVDTs, but they require some very specific electronic sensor arrangements (Wheatstone bridge) and need to be mounted on flexible frames (Beedlaw et al., 1986; Link et al., 1998). Commercial units are also available, but their price seems to hinder their widespread adoption, as a large number of units would be needed for both research and orchard management purposes. One aspect that bears considerably on the choice of sensor and of the materials used in constructing field probes is their ruggedness and accuracy under varying environmental conditions, including large temperature, precipitation, and air moisture changes. This is more so when the degree of accuracy required of the sensor is in the order of $10-20 \mu \mathrm{m}$, as is desirable in studies dealing with daily variations of fruit diameter.

In this work we describe an inexpensive, custom-built device for the accurate measurement of fruit diameter variations over time, based on a low-cost linear potentiometer. The sensor is described, and data on the signal stability over a range of temperatures and from an actual study of fruit growth physiology are provided as a example of the potential of such an instrument.

\section{Materials and Methods}

Gauge description. The gauge consists of a light, stainless steel frame, supporting an electronic sensor (Fig. 1). The sensor is a linear potentiometer (Megatron Elektronik MM10, $50 \mathrm{~K} \Omega$; Megatron Elektronik AG \& Co., Munich, Germany) whose actual cost is around $\$ 65(50 €)$. This, coupled to a cost below $\$ 13$ (10€, depending on the size of the production run) puts the cost of the gauge around $\$ 80$ (ca. $60 €$ ).

The potentiometer is fitted with a mobile metal plunger that touches the fruit with a small aluminium disc. The plunger is pushed against the cheek of the fruit by a light spring $\left(0.06 \mathrm{~N} \mathrm{~mm}^{-1}\right)$ so that it can track variations in fruit diameter, with the sensor output changing in proportion to the distance traveled. The plunger has an electric stroke of $11 \pm 0.05 \mathrm{~mm}$ with resolution $<0.01 \mathrm{~mm}$. Further details of this potentiometer are available from the technical datasheet provided by the company (<http://www.megatron.de/export/ Linear_Motion/MM10/DB_MM10_engl.pdf $>$ ). To operate, the sensor needs to be interfaced to a data-logger, which, after exciting the sensor at $2000 \mathrm{mV}$, reads, converts, and stores the output signal. A simple wiring diagram is reported in Fig. 1. Output tensions are in the 0 to $2000 \mathrm{mV}$ range and can be converted to length unit ( $\mathrm{mm}$ ) using a specific calibration coefficient.

The supporting stainless steel frame is shown in Fig. 2, which includes dimensions of the different components in $\mathrm{mm}$. The sensor is mounted onto a vertical metal strip, which can slide on the horizontal slide holder to which it is attached by two screws. A second vertical metal strip, with a thin plate at its top, is permanently fixed at the distal end of the horizontal slide bar. The vertical strip holding the sensor can be moved along the horizontal slide bar by loosening the two screws. This allows the gauge to easily operate on fruit of different size, up to $100 \mathrm{~mm}$ in diameter. During operation, the fruit is placed between the round disc at the end of the sensor plunger and the thin plate at the top of the fixed vertical strip. The frame allows the fruit's natural position relative to the branch to be maintained. The entire structure weighs about $40 \mathrm{~g}$ and can be easily fixed to a branch using plastic tape.

Calibration. After interfacing to a Campbell CR10X data-logger (Campbell Scientific Ltd., Leicestershire, United Kingdom), sensors were calibrated by moving the plunger by 


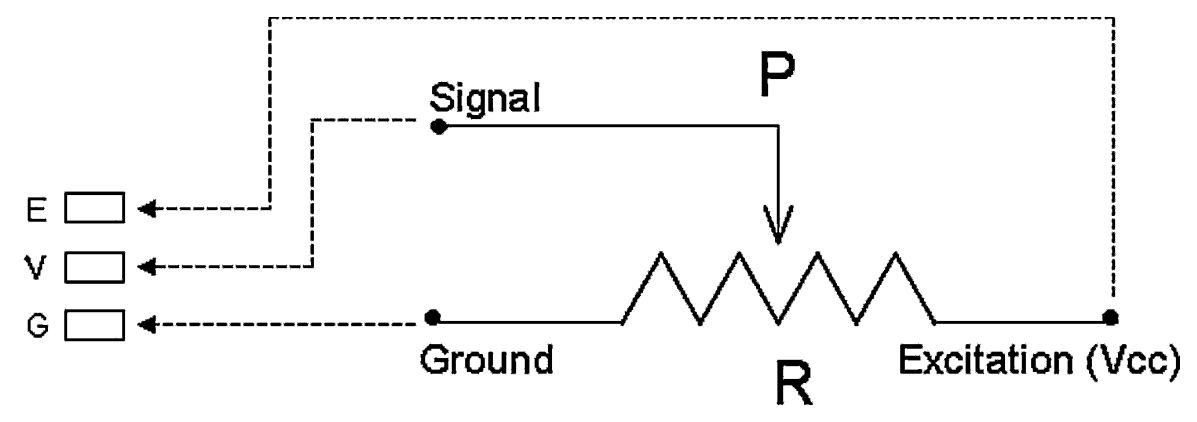

DATALOGGER

Fig. 1. Wiring diagram for the potentiometer, showing also the types of ports required for the data-logger interface. Signal, ground, and excitation wires must be connected to the voltage reading (V), ground (G), and excitation (E) ports of the data-logger.

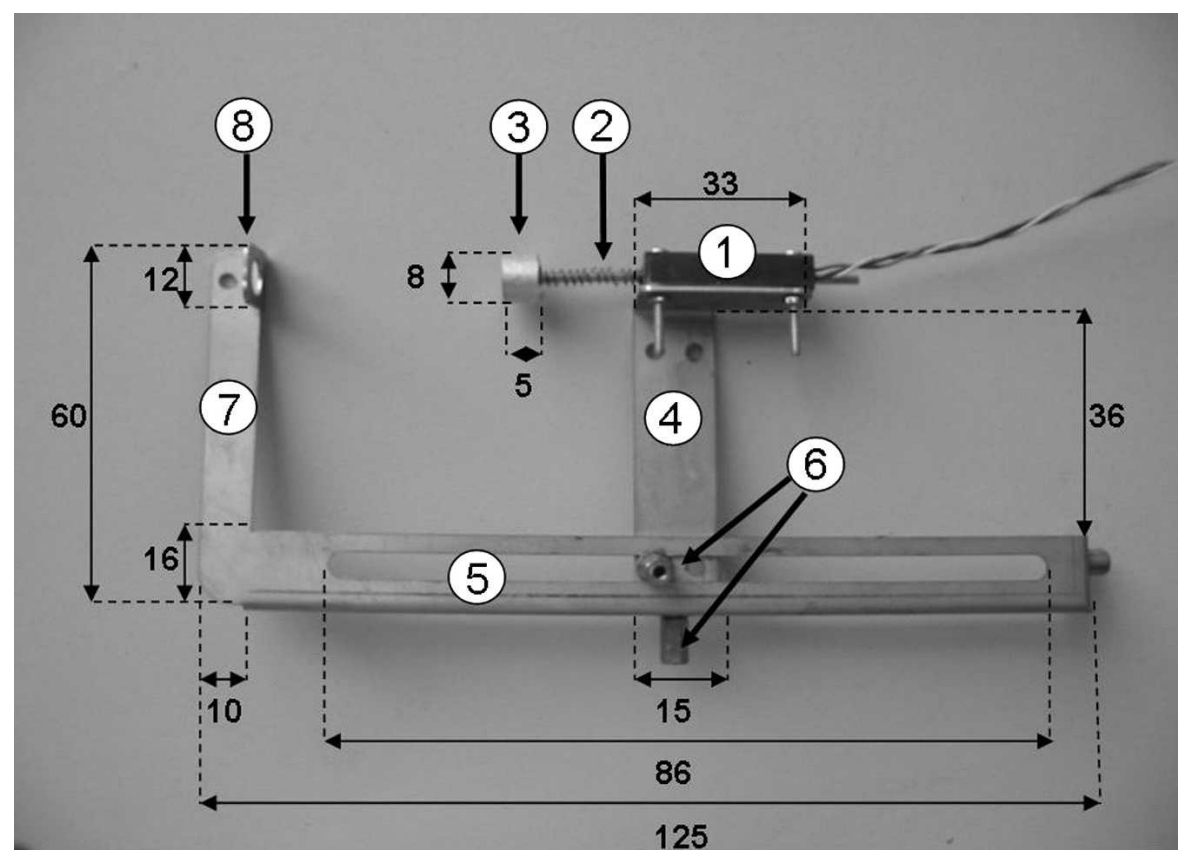

Fig. 2. Photograph of the gauge used for continuous measurement of fruit diameter. Numbers in white circles indicate the gauge components: (1) sensor; (2) sensor plunger with spring; (3) contact aluminium disc; (4) vertical sliding strip supporting the sensor; (5) horizontal slide holder; (6) adjusting screws; (7) fixed vertical strip; (8) fruit stopper. Dimensions are expressed in mm.

predetermined steps and recording the relative tension signals. Each step corresponded to $0.7 \mathrm{~mm}$ and was traveled by turning a $0.7 \mathrm{~mm}$ threaded screw pushed against the plunger end $360^{\circ}$. The entire plunger travel was scanned this way, for four sensors. For each step, $\mathrm{mV}$ and $\mathrm{mm}$ data were plotted and the linear equation slopes, regression coefficients, and $P$ values were calculated. A general conversion coefficient between tension and displacement was obtained by averaging the slopes for the four sensors.

Temperature test. The response to temperature of both the sensor and the supporting structure were tested. Sensor output changes due to temperature were evaluated by monitoring the signal at about $0,700,1400$, and $1950 \mathrm{mV}$ of the plunger travel at $25{ }^{\circ} \mathrm{C}$ for three sensors, which were then submitted to temperature changes in the $5-60{ }^{\circ} \mathrm{C}$ range. A
LINEAR POTENTIOMETER

different orchards at the experimental farm of the University of Bologna, Cadriano, Bologna, Italy. As an example of the gauge performances we report data from 'Red Gold' nectarine fruit (52-mm average diameter) monitored at cell expansion [105 d after full bloom (DAFB)]. Data were recorded at userdefined intervals (12-15 min) by the CR10X data-logger to which the gauges were connected by 3-wire electric cables 3-12 m long.

\section{Results and Discussion}

Calibration. Linear and highly significant relationships between voltage and plunger travel were found in all cases, with $R^{2}$ values $>0.999$. The average slope in the $\mathrm{mV}-\mathrm{mm}$ conversion equation was $5.4 \times 10^{-3}\left( \pm 5 \times 10^{-5}\right.$ $\mathrm{SD})$. This standard deviation corresponds to a measurement error within $1 \%$, due to variability among sensors. The linear response of the potentiometer allows direct voltage to displacement conversion derived from the slope of the $\mathrm{mV} / \mathrm{mm}$ relationship. Fruit diameter variation over time is calculated as the difference between the last and the initial value recorded over the time interval. In peach, during cell expansion, the error incited by sensor variability would fall within $7 \times 10^{-3} \mathrm{~mm} \cdot \mathrm{d}^{-1}$, for a fruit growing as reported in Fig. 3 .

Temperature test. Temperature tests on single sensors showed maximum deflections of $\pm 1 \mathrm{mV}$ from the tension value recorded at $25^{\circ} \mathrm{C}$, over the temperature range considered $\left(5-60{ }^{\circ} \mathrm{C}\right)$, which corresponds to $0.1 \%$ of the excitation range $(0-2000 \mathrm{mV})$. Similar results were obtained at $0,700,1400$, and $1900 \mathrm{mV}$, indicating that the effect of temperature on the sensor signal is independent of plunger position. The test performed on the entire gauge structure showed similar signal deflections $( \pm 1 \mathrm{mV})$ over the same temperature range, indicating no significant effect of frame expansion or contraction in response to temperature changes. This result is about half the expected error calculated for a general thermal expansion coefficient for stainless steel of $17.3 \mathrm{ppm} /{ }^{\circ} \mathrm{C}$ (Lide, 1992).

Taking into account the frame and sensor temperature responses, a maximum total deflection of $4 \mathrm{mV}$ in the output signal should be expected over the temperature range tested, i.e., $0.022 \mathrm{~mm}$. This error can be ignored to each sensor, and both temperature and tension data were collected simultaneously every second by the Campbell CR10X datalogger. Expansion or contraction of the frame due to the material temperature response were quantified by submitting three gauges, each with a thermocouple applied to the frame, to temperatures between 5 and $60{ }^{\circ} \mathrm{C}$. In this test, the gauges were arranged so that the plungers touched the metal plates at different lengths of their travel, generating signals (at $25^{\circ} \mathrm{C}$ ) of 700,1400 , and $1900 \mathrm{mV}$ for the first, second, and third gauge, respectively. Both thermocouples and gauges were connected to the CR10X data-logger, and temperature and tension data were collected simultaneously every second.

Field measurements. Up to 30 gauges were field-tested over three growing seasons, in

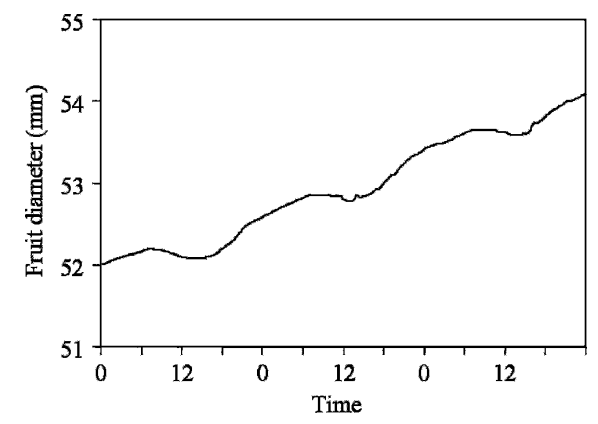

Fig. 3. Patterns of peach fruit diameter growth over $3 \mathrm{~d}$ at 105 DAFB (stage III). 
because under normal field conditions a temperature variation of $20^{\circ} \mathrm{C}$ may cause an error $<0.01 \mathrm{~mm}$, which almost equates the sensor resolution. This sum of errors due to sensor resolution $(<0.09 \%)$, $\mathrm{mV}-\mathrm{mm}$ conversion (1\%), and temperature effects on both the potentiometer $(0.1 \%)$ and the frame $(0.1 \%)$ is comparable or even lower than the accuracy reported for similar devices based on LVTDs (Higgs and Jones, 1984) or strain gauges (Link et al., 1998). However, diurnal changes in fruit water status can affect fruit deformability, thus changing the "apparent" diameter of the fruit when this is measured by a spring-loaded sensor. This could be avoided by using some glue to make the plunger "stick" to the fruit cheek. Nevertheless, glue may cause necrosis on the fruit epidermis and affect fruit diameter measurements. Also, glue may be easily removed or inactivated by environmental agents (i.e., rain), preventing stable and continuous measurements of fruit growth. Additional fruit diameter changes might occur due to thermal expansion/contraction of the fruit in response to temperature. Both these effects are difficult to control and quantify regardless of the sensor or frame adopted, and no attempt was made to account for them in our measurements.

Field measurements. Clear patterns of fruit growth with low background noise were detected in all instances where this instrument was used, regardless of fruit size or growth stage. Data reported in Fig. 3 provide a clear example of this.

The gauge presented in this work is similar in principle and construction to a digital caliper. Nevertheless, this instrument proved its worth in the course of several studies over three seasons. The adjustable frame allows a single sensor to monitor fruit growth over the entire season, despite a plunger displacement of only $11 \mathrm{~mm}$ because the "jaw" of the gauge can be enlarged easily in the field by loosening the screws and moving the metal strip supporting the sensor. An example of the reproducibility of the measurements of peach fruit growth is shown in Fig. 3. Thanks to its light weight and adaptable structure, the gauge can be easily applied to fruits of different size and shape. In peach, the displacement of the plunger allows 8-9 d of measurement during cell division and cell expansion, and $>20 \mathrm{~d}$ of measurement during pit hardening, without the need to adjust the gauge. This is a relevant feature in comparison with other devices, such as those based on strain gauges that are limited by the maximum deformation of the sensor (Beedlaw et al., 1986; Link et al., 1998). In addition, the sensor adopted for our gauge can be substituted by other models that feature longer displacements, thus allowing very long periods of measurement without resetting. The reduced need for resetting may be particularly useful if the gauges are applied to commercial orchards, for example, to regulate irrigation on the basis of fruit daily shrinkage (Huguet, 1985) or for real-time monitoring of fruit growth to forecast harvest fruit size.

After three seasons of field use without protection from environmental factors, only two of the 30 gauges used had problems, probably due to wear of the sensor circuit or to water infiltration into the circuitry. However, such a small number of substitutions was considered acceptable, particularly given the low cost of the sensor.

\section{Conclusions}

The gauge described herein integrates low-cost, simple, and rugged construction with ease of use and a low frequency of resetting. Furthermore, the linear potentiometer adopted can be easily calibrated and features good temperature stability under demanding field conditions. The gauge can also be used in the same configuration as a dendrometer, thus expanding its range of application.

\section{Literature Cited}

Araki, T., M. Kitano, and H. Eguchi. 2000. Dynamics of fruit growth and photoassimilate translocation in tomato plant (Lycopersicon esculentum Mill.) under controlled environment. Acta Hort. 534:85-92.

Beedlaw, P.A., D.S. Daly, and M.E. Thiede. 1986. A new device for measuring fluctuations in plant stem diameter: implications for monitoring plant responses. Environ. Monit. Assess. 6:277-282.

Berger, A. and G. Selles. 1993. Diurnal fruit shrinkage: a model, p. 261-267. In: M. Borghetti, J. Grace, and A. Raschi (eds.). Water transport in plants under climatic stress. Cambridge Univ. Press., Cambridge, England.

Garnier, E. and A. Berger. 1986. Effect of water stress on stem diameter changes of peach trees growing in the field. J. Appl. Ecol. 23:193-209.

Huguet, G. 1985. Appreciation de l'état hidrique d'une plante à partir de variations micrométrique de la dimensions des fruits et des tiges au cours de la journée. Agronomie 5:733-741.

Higgs, K.H. and H.G. Jones. 1984. A microcomputer-based system for continuous measurement and recording fruit diameter in relation to environmental factors. J. Expt. Bot. 35: 1646-1655.

Jones, H.G. and K.H. Higgs. 1982. Surface conductance and water balance of developing apple (Malus pumila Mill) fruits. J. Expt. Bot. 132:67-77.

Lang, A. 1990. Xylem, phloem and transpiration flows in developing apple fruits. J. Expt. Bot. 41:645-651.

Lide, D.R. 1992. Handbook of chemistry and physics. 73rd ed. CRC Press, Boca Raton, FL.

Link, S.O., M.E. Thiede, and M.G. Van Bavel. 1998. An improved strain gauge device for continuous field measurement of stem and fruit diameter. J. Expt. Bot. 49:1583-1587.

Morandi, B. 2006. Xylem and phloem regulation in peach fruit growth. Univ. of Bologna, $\mathrm{PhD}$ Dissertation.

Përämaki, M., E. Nikinmaa, S. Sevanto, H. Hilvesniemi, E. Siivola, P. Hari, and T. Vesala. 2001. Tree stem diameter variation and transpiration in Scot pine: an analysis using a dynamic sap flow model. Tree Physiol. 21: 889-897.

Tromp, J.P. 1984. Diurnal fruit shrinkage in apple as affected by leaf water potential and vapour pressure deficit of the air. Scientia Hort. 22: $81-87$.

Tukey, L.D. 1964. A linear electronic device for continuous measurement and recording of fruit enlargement and contraction. Proc. Amer. Soc. Hort. Sci. 84:653-660. 